\title{
A caracterização do risco sanitário nos processos administrativos da vigilância sanitária
}

\author{
The characterization of health risk in health surveillance proceedings
}

\section{Max Rogério Alves}

Advogado, especialista em Direito Sanitário e em Direito Processual Civil. Brasília, Brasil.

Resumo: Estudo da caracterização do risco sanitário (avaliação e gerenciamento de risco) nos processos administrativos da vigilância sanitária, a partir de um estudo de caso relativo ao controle sanitário de portos, aeroportos e fronteiras. A análise de decisões tomadas no âmbito de processos sanitários permitiu evidenciar que o grau de risco é superficialmente tratado neles, inferindo-se que a caracterização do risco nos referidos processos aproxima-se mais da aplicação do senso comum do que de uma abordagem científica.

Palavras-chave: Vigilância sanitária; processo sanitário; risco.

Resumen: Estudio de la caracterización del riesgo para la salud (evaluación y gestión de riesgo) en los procesos administrativos de la vigilancia sanitaria, a partir de un estudio de caso sobre el control sanitario de puertos, aeropuertos y fronteras. El análisis de las decisiones tomadas en el ámbito de los procesos sanitarios ha permitido evidenciar que el grado de riesgo es superficialmente tratado en ellos, infiriéndose que la caracterización del riesgo en esos casos está más cerca de la aplicación del sentido común que de un enfoque científico.

Palabras clave: Vigilancia sanitaria; proceso sanitario; riesgo.

\begin{abstract}
Characterization of health risk (assessment and risk management) in administrative proceedings of health surveillance, from a case study concerning the sanitary control of ports, airports and frontiers. The analysis of decisions made under sanitary proceedings shows that the determination of riskiness is superficially treated in them, concluding that the risk characterization, in those cases, is closer to the application of common sense than a scientific approach.
\end{abstract}

Keywords: Health surveillance; surveillance proceeding; health risk.

\section{Introdução}

O entendimento legal de vigilância sanitária é de que ela constitui um conjunto de ações capazes de eliminar, diminuir ou prevenir riscos à saúde e de 
intervir nos problemas sanitários decorrentes do meio ambiente, da produção e circulação de bens e da prestação de serviços de interesse da saúde (Lei no 8.080/90, artigo $\left.6^{\circ}, \S^{\circ}\right)$.

Um grande leque de produtos e serviços fica, dessa forma, submetido aos regulamentos sanitários, já que, com relação a sua abrangência, ela engloba o controle de bens de consumo que, direta ou indiretamente, se relacionem com a saúde, compreendidas todas as etapas e processos, da produção ao consumo, e o controle da prestação de serviços que se relacionam direta ou indiretamente com a

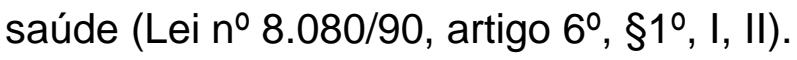

O trabalho da vigilância sanitária, em última análise, consiste em identificar agentes ou processos passíveis de gerar perigos físicos, biológicos ou culturais para a saúde pública. Consequentemente, a avaliação do risco associado a esses agentes e processos, com vistas a mensurar a exposição da população a agentes nocivos, também é inerente à ação da vigilância sanitária. Dessa forma, é após identificar e avaliar o risco que a Administração Pública regulamenta e normatiza a questão e passa a fiscalizá-la.

Ao verificar o ilícito sanitário - existência de risco sanitário -, lavra-se o auto de infração que constitui 0 ato a partir do qual tem início o processo administrativo da vigilância sanitária (Lei no 6.437/77, artigo 12). O processo administrativo que conforma a ação fiscalizadora da vigilância sanitária decorre, portanto, do auto de infração.

O processo administrativo da vigilância sanitária - também conhecido por 'processo administrativo sanitário' ou simplesmente 'processo sanitário' - tem rito próprio e rege-se pela Lei no $6.437 / 77$. Em seus autos, são organizados todos os procedimentos realizados desde a inspeção sanitária até a decisão final sobre o caso, a ser emitida pela autoridade julgadora ou, em caso de recurso administrativo, pelo órgão colegiado de direção da agência reguladora.

Sua lei regente determina que a autoridade sanitária, quando da imposição da pena e o estabelecimento de sua graduação, leve em conta a gravidade do fato verificado pela inspeção, tendo em vista suas consequências para a saúde pública (Lei no 6.437/77, artigo 6ำ, II). A referida determinação legal trata, portanto, da necessária caracterização do risco no âmbito do processo administrativo sanitário. 
Entende-se que uma suficiente caracterização da gravidade da infração - proporcional ao risco sanitário envolvido - é elemento crítico para a ação fiscalizatória, em especial para que a autoridade imponha a pena e defina sua graduação, nos termos da lei.

É por meio da caracterização do risco gerado pelo ilícito sanitário que se pode ter ideia da magnitude dos malefícios que ele pode causar. Quando a autoridade sanitária não considera o elemento gravidade do risco, pode incorrer em decisões arbitrárias e ineficientes por ausência de embasamento quanto às consequências do ato infracional, ou na aplicação de sanções desproporcionais ${ }^{1}$.

Por isso, entende-se que o estudo e a problematização do tema enuncia atribuições do Direito Sanitário por estar associado ao aumento da eficácia da ação da vigilância sanitária e da consciência da responsabilidade sanitária da sociedade em geral.

\section{Metodologia}

Utilizou-se a técnica de estudo de caso, com a análise de um processo administrativo sanitário.

O caso foi escolhido em razão da riqueza de detalhes e por se tratar de um caso específico, no qual uma única decisão foi proferida em seis processos decorrentes de autos de infração lavrados contra uma única empresa, em momentos diversos. O estabelecimento autuado era prestador de serviços, localizado em área portuária, porquanto regulado pela vigilância sanitária.

Seu estudo permitiu caracterizar como se realizou a manifestação sobre a gravidade do risco nos processos analisados, desde a verificação da matéria de fato pelo autuante até a decisão final da autoridade julgadora.

\footnotetext{
1 A caracterização equivocada do risco, por menor que seja a falha em sua apuração, poderá comprometer a sobrevivência do empreendimento, haja vista que pequenos comerciantes e microempresários terão dificuldades em arcar com os grandes valores das sanções pecuniárias.
} 


\section{Competência do Estado em matéria de vigilância sanitária}

\subsection{Controle sanitário e poder de polícia}

O controle sanitário é regido pela legislação sanitária específica, cujo cumprimento deve ser garantido pelo poder de polícia do Estado, que se explicita pela fiscalização sanitária (Waldman, 1991).

De forma sucinta, Di Pietro (2007) apresenta o conceito moderno, adotado no Direito brasileiro, do poder de polícia como "a atividade do Estado consistente em limitar o exercício dos direitos individuais em benefício do interesse público". A existência de um 'poder de polícia' justifica-se, para Miranda (2007), pela necessidade de ajustar-se o exercício dos direitos conferidos a cada pessoa com o bem estar de toda a sociedade. Assim, busca-se conciliar o interesse individual com o interesse coletivo.

O poder de polícia, portanto, constitui um dos poderes que possui a Administração Pública para cercear determinados direitos privados em benefício do interesse coletivo. Em se tratando de controle sanitário, serão cerceados direitos de pessoas físicas ou jurídicas em favor da saúde coletiva.

Para que o exercício do poder de polícia se faça dentro dos ditames legais e para que não sejam eliminados os direitos individuais, alguns autores indicam regras a serem observadas pela polícia administrativa:

1. a da necessidade, em consonância com a qual, a medida de polícia só deve ser adotada para evitar ameaças reais ou prováveis de perturbações ao interesse público;

2. a da proporcionalidade, (...), que significa a exigência de uma relação necessária entre a limitação do direito individual e o prejuízo a ser evitado;

3. a da eficácia, no sentido de que a medida deve ser adequada para impedir o dano ao interesse público. (Di Pietro, 2007)

Tais regras devem ser sempre seguidas para que o poder de polícia seja adequadamente aplicado ao caso concreto. Sua inobservância enseja a realização de ações sancionadoras desnecessárias, desproporcionais ou inadequados, caracterizando a arbitrariedade na atuação da Administração Pública. 


\subsection{Portos, aeroportos e fronteiras como áreas que se sujeitam às leis sanitárias}

O controle sanitário de portos, fronteiras e, mais recentemente, de aeroportos e estações ferroviárias de conexões internacionais, constitui uma das práticas mais antigas de saúde pública (Waldman, 1991).

Ele é exercido por meio do poder de polícia e deve ser pautado na legislação sanitária vigente, que atribui à Anvisa exercê-lo na forma de vigilância sanitária de portos, aeroportos e fronteiras, podendo essa atribuição ser supletivamente exercida pelos estados, pelo Distrito Federal e pelos municípios (art. $2^{\circ}$, IV, da Lei no 9.782/99).

Consoante o artigo 6ํㅜ, caput, da Lei de criação da Anvisa, a agência terá por finalidade institucional promover a proteção da saúde da população por meio do controle sanitário da produção e da comercialização de produtos e serviços submetidos à vigilância sanitária, inclusive dos ambientes, dos processos, dos insumos e das tecnologias a eles relacionados, bem como o controle de portos, aeroportos e fronteiras. Os portos, aeroportos e fronteiras, portanto, constituem áreas que, historicamente, sujeitam-se à legislação sanitária e são de plena competência da Agência Nacional de Vigilância Sanitária, seja para fiscalização ou para execução de atividades de vigilância.

\section{Avaliação e gerenciamento do risco}

Sem que as pessoas percebam, rotineiramente, elas realizam avaliações de risco. Alguém que antes de sair de casa consulte o relógio, verifique as condições do trânsito, o fato de estar chovendo, a distância da casa para o trabalho, entre outros detalhes, realiza uma avaliação de riscos e, ao mesmo tempo, os gerencia na busca de seu interesse.

Essa avaliação do risco, no entanto, realiza-se por meio do senso comum, de modo que cada sujeito a executa de um modo diferente, sob a influência de critérios pessoais. Já a análise científica de risco é definida por Molak (1997) como um conjunto de conhecimentos (metodologia) que avalia e deriva a probabilidade de acontecer um efeito adverso causado por um agente (químico, físico, biológico e outros), processos industriais, tecnologia ou processo natural. "No campo sanitário", ressalta Lucchese (2008), "os efeitos adversos são quase sempre relacionados a algum dano à saúde, às doenças e, até mesmo, à morte". 
Um dos maiores desafios para a ação regulatória do Estado moderno na área sanitária é a avaliação do risco das novas tecnologias, sejam elas substâncias, aparelhos ou serviços (Lucchese, 2008).

Para o melhor exercício dessa ação regulatória, diferencia-se 'avaliação do risco' de 'gerência do risco', que consistem, segundo o National Research Council (1983), comitê da Academia Nacional de Ciências dos Estados Unidos, e citado por Lucchese (2008), em:

a) Avaliação do risco - de natureza mais científica, consiste no uso de bases concretas de dados para definir os efeitos de uma exposição (indivíduos ou população) a materiais ou situações; busca medir, por exemplo, o risco associado a uma substância.

b) Gerência do risco - de orientação mais político-administrativa, é o processo de ponderar as alternativas de políticas e de selecionar a ação regulatória mais apropriada, integrando os resultados da avaliação do risco com as preocupações sociais, econômicas e políticas para chegar a uma decisão; decide o que fazer com o risco avaliado.

Delduque (2010) salienta que a avaliação do risco é objetiva e configura-se em um processo técnico. Por sua vez, o gerenciamento constitui etapa da ação, é decisão discricionária, por vezes, e tem por base critérios políticos. "A política de avaliação do risco", ressalta Lucchese, "difere da política de gerência do risco, que se caracteriza por decisões para o âmbito externo e tem fundamentos mais amplos, ligados à cultura, à economia e às características sociais de cada lugar”.

Desta feita, segundo a lição de Lucchese (2008), a caracterização do risco consiste em um dos estágios da avaliação do risco, de forma que aquela:

descreve a natureza e, com frequência, a magnitude do risco humano: a substância é de fato perigosa? É bastante ou levemente perigosa? Com base na curva de dose-resposta e nos resultados encontrados sobre a exposição é possível descrever e categorizar o risco avaliado?

Ainda, assevera o autor, que: "a avaliação do risco à saúde pode ser tarefa simples quando há relação altamente imediata e compreensível entre um dano e a sua causa, mas pode ser complexa ao envolver riscos pequenos ou exposições demasiadamente longas."

A dificuldade para avaliação do risco exsurge diante de diversos fatores, entre eles a realização em estágios, o tempo necessário, custo e a exigência de pessoal, técnicas e equipamentos sofisticados. Dependendo do caso, o processo pode ser demorado e complexo (Lucchese, 2008). 
Ao dissertar sobre o saber e a ignorância, Boaventura de Souza Santos explica que o saber moderno, dividido em vocação crítica e vocação de cumplicidade, atingiu um ponto em que o conhecimento distanciou-se tanto do senso comum que gerou uma ruptura epistemológica. O resultado disso foi a ruptura entre a ciência moderna e o senso comum. Ele acredita que, "uma vez realizada essa ruptura, o ato epistemológico mais importante é romper com ela e fazer com que o conhecimento científico se transforme num novo senso comum" (Santos, 1993).

Lucchese (2008), ao analisar o interesse de Santos sobre o tema, afirma que "o autor sonha com uma configuração cognitiva em que um e outro tipo de conhecimento supere a si mesmo para dar lugar a uma nova forma de conhecimento; um senso comum legitimado cientificamente".

Santos (1995, p.41), vislumbrando uma ciência pós-moderna, afirma que o novo conhecimento somente se realiza enquanto tal na medida em que se converte em senso comum. E aposta na factibilidade dessa conversão, considerando as possibilidades da hermenêutica e o extraordinário desenvolvimento tecnológico da comunicação, que poderia aprofundar sua competência comunicativa e cognitiva, transformando o saber científico em saber prático, que ajude as pessoas a tomarem decisões no dia a dia, conferindo sentido $e$ autenticidade à existência. (Lucchese, 2008)

Em uma decisão sujeita à esfera da competência administrativa de uma agência reguladora, o que se espera é que ela tenha suporte técnico-científico, haja vista que a própria criação dessas agências explicita o seu caráter de especialização.

Mais uma vez, aproveitam-se as lições de Lucchese (2008),

As agências regulatórias, com sua expertise, seus objetos e assuntos científicos a respeito de coisas que provocam impacto no cotidiano dos indivíduos, parecem constituir centros de fantástica possibilidade difusora dessa conciliação entre o conhecimento científico e o senso comum, fazendo com que o cidadão comum entenda com mais confiança o que acontece pelo mundo.

Em sentido amplo, agência reguladora, no Direito brasileiro, representa qualquer órgão da Administração Direta ou entidade da Administração Indireta com função de regular matéria específica (Di Pietro, 2007). Assim, a criação das agências reguladoras está intrinsecamente ligada à questão da especialidade na área que lhe diz respeito.

Dessa forma, percebe-se uma ligação entre a aplicação de conhecimentos técnico-científicos para constatação do risco sanitário e a legitimidade das decisões 
administrativas, na medida em que a decisão que aplicar uma sanção, além de amparar-se no conhecimento especializado da agência reguladora, deve ter o conteúdo claro o suficiente para que o cidadão possa compreender sua conduta irregular ou o resultado que esta poderia causar.

Acredita-se que esse esclarecimento técnico-científico, desde que claro para o cidadão comum, possa resultar em maior conformação para o administrado que, quando não compreende a ilicitude de sua conduta, não mede esforços para levar o tema à discussão em todas as instâncias possíveis.

Nesse sentido, Delduque (2010) analisa esse caráter conflituoso acerca da atuação da vigilância sanitária:

O espaço de atuação da vigilância sanitária é permeado por constante conflito, posto que é seu mister diminuir ou eliminar os riscos advindos do meio ambiente, da produção e circulação de bens, da prestação de serviços que afetem direta ou indiretamente a saúde da população limitando, por vezes, a esfera de atuação da atividade individual e econômica. Tais conflitos, na ausência de instâncias para a sua gestão eficaz, acabam por desaguar no Poder Judiciário.

Ademais, a relevância da caracterização do risco nos processos sanitários relaciona-se diretamente com a aplicação da penalidade e sua dosimetria, a ser feita partir da consideração da gravidade do fato diante das consequências para a saúde pública, de acordo com o artigo 6º , II, da Lei ํㅜ 6.437/77. Logo, a maior gravidade do fato e suas consequências para a saúde pública - a avaliação do risco - são fatores de imprescindível consideração para a penalização daquele que infringir as leis sanitárias.

\section{A caracterização do risco sanitário nos processos administrativos da vigilância sanitária}

De acordo com o artigo 15, da Lei no 6.437/77, "a autoridade que determinar a lavratura do auto de infração ordenará, por despacho em processo, que o autuante proceda à prévia verificação da matéria de fato". Essa determinação implica em que o servidor autuante deve constatar o risco sanitário da situação concreta em questão.

Caso não seja constatado o risco nesse momento, entende-se que, segundo dispõe o artigo 22, $\S 1^{\circ}$, desse diploma legal, "antes do julgamento da defesa ou da impugnação a que se refere este artigo deverá a autoridade julgadora ouvir o 
servidor autuante, que terá o prazo de dez dias para se pronunciar a respeito". Há, portanto, previsão legal para, em nova oportunidade, a manifestação do servidor autuante sobre o risco avaliado.

Quanto à autoridade julgadora, é o artigo 6으, inciso II, da Lei ํㅜ 6.437/77, que dispõe sobre a determinação de se levar em conta a gravidade do fato - tendo em vista as suas consequências para a saúde pública - para a imposição da pena e a sua graduação, nesses termos:

Art. 6․ Para a imposição da pena e a sua graduação, a autoridade sanitária levará em conta:

II - a gravidade do fato, tendo em vista as suas consequências para a saúde pública;

O dispositivo em comento possui evidente caráter impositivo, na medida em que, por meio de sua leitura, depreende-se que o legislador optou por empregar o verbo no modo imperativo afirmativo - levará -, notadamente, com o interesse de determinar uma ordem ao julgador para que a cumpra quando da imposição da pena e o estabelecimento de sua graduação. De acordo com o referido dispositivo, a análise da gravidade do fato com base em suas consequências para a saúde pública constitui requisito de análise obrigatória para a imposição e a graduação da pena pela autoridade sanitária.

Daí surge o interesse em verificar como se trata a questão do risco nos processos administrativos da vigilância sanitária decorrentes de autos de infração.

O assunto representa fonte de grande discussão e torna perceptível o fato de, em alguns casos, apenas as opiniões sobre ele mostrarem-se divergentes, haja vista que o embasamento argumentativo é feito sobre um único dispositivo legal, o próprio artigo $6^{\circ}$, inciso II, da Lei $n^{\circ}$ 6.437/77.

\section{Resultados}

Foram analisados seis processos administrativos com o objetivo de explicitar e esclarecer como é abordado o tema risco nos processos administrativos sanitários.

Esses processos, ante o interesse da Administração e sob a consideração de princípios como os da celeridade e da economia processual, foram analisados 
pela autoridade julgadora em uma única decisão, apesar de cada um deles decorrer de autos de infração diversos.

Em se tratando de uma única decisão para vários processos, tem-se que cada um deles seguiu um trâmite específico até a prolação da decisão, com isso, poder-se-á notar como se abordou a questão do risco sanitário em cada caso.

Trata-se a autuada de empresa portuária que opera praticamente durante todos os dias do ano. Em seus milhares de metros quadrados de área há uma extensa faixa de atracação, sede administrativa, áreas alfandegadas, armazéns e restaurante, de modo que suas atividades são diretamente atingidas pela competência da fiscalização da vigilância sanitária.

Nesse contexto, a empresa sofreu autuações em diferentes situações, as quais serão elencadas a seguir.

a) A primeira delas refere-se à constatação de "resíduos" fora dos contendores, provenientes das embarcações (próximo à área de armazenamento temporário dos resíduos)". Essa irregularidade foi tipificada no artigo $51, \S 5^{\circ}$, da Resolução da Diretoria Colegiada - RDC nำ56, de 6 de agosto de 2008. O referido dispositivo legal aduz que:

Art. 51 Quando os resíduos forem acondicionados em sacos, estes deverão ser de material resistente à ruptura e vazamento, impermeável, respeitados os limites de peso, devendo ser substituídos sempre que necessário, ou quando atingirem $2 / 3$ de sua capacidade, ou pelo menos uma vez ao dia, sendo proibido o seu esvaziamento ou reaproveitamento.

$\S 5^{\circ}$ Os sacos devem permanecer durante todas as etapas de gerenciamento dentro de recipientes de acondicionamento.

No decorrer no processo, constata-se que os resíduos provenientes das embarcações encontravam-se em sacos plásticos, contudo, foram armazenados fora dos devidos recipientes de acondicionamento, os quais o servidor autuante chamou de contendores. Em sua defesa, a empresa alega que os resíduos eram constituídos de plásticos e papel.

\footnotetext{
${ }^{2}$ A RDC ํㅜ 56, de 6 de agosto de 2008, em seu Capítulo I, artigo 1ํ, XL, define resíduos sólidos como: resíduos nos estados sólido e semisólido, originários de atividade: industrial, doméstica, hospitalar, comercial, agrícola, de serviços e de varrição. Incluem-se nessa definição os lodos provenientes de sistemas de tratamento de água, aqueles gerados em equipamentos e instalações de controle de poluição e determinados líquidos cujas particularidades tornem inviável seu lançamento na rede pública de esgotos ou corpos d'água. Excluem-se dessa definição os excrementos humanos.
} 
Este processo apresenta uma situação específica: no momento descrito pelo artigo 15, da Lei $\mathrm{n}^{\circ}$ 6.437/77, durante a prévia verificação da matéria de fato, o servidor autuante não fez qualquer referência ao risco sanitário, contudo, ao perceber a falha, o Coordenador de Vigilância Sanitária, entre outras considerações, manifestou-se sobre o risco nos seguintes termos:

Considerando que a conduta da empresa autuada contribuiu para a existência do RISCO SANITÁRIO, configurando o cometimento da infração sanitária. (Destaque no original).

b) No segundo processo, constatou-se a mesma irregularidade, "resíduos fora dos contendores", logo, de idêntica tipificação legal: artigo 51, §5º, da RDC ํㅜ 56, de 6 de agosto de 2008.

A situação é bem similar à descrita no primeiro processo, haja vista que os resíduos foram caracterizados como estopas, garrafas plásticas, papéis, entre outros materiais que se encontravam em sacos plásticos, contudo, dentro de uma cesta sem tampa.

Nesse segundo processo administrativo, o servidor autuante também não realizou qualquer comentário acerca do risco quando da verificação da matéria de fato. Assim, foi o Coordenador de Vigilância Sanitária que, entre outras considerações, manifestou-se sobre o risco nos mesmos termos apresentados anteriormente:

Considerando que a conduta da empresa autuada contribuiu para a existência do RISCO SANITÁRIO, configurando o cometimento da infração sanitária. (Destaque no original).

c) O terceiro processo constatou a irregularidade de "resíduos fora dos contendores, provenientes das embarcações". A tipificação legal foi descrita como a do artigo 19, da RDC nํ56, de 6 de agosto de 2008, a qual aduz:

Art. 19. O transporte das áreas de geração às áreas de armazenamento temporário deverá ser realizado através de carros coletores ou dos próprios recipientes de acondicionamento, de forma a não interferir com o fluxo de meios de transporte e de pessoas.

Não há nos autos qualquer informação sobre quais materiais compunham os resíduos em questão e, mais uma vez, o autuante não realizou qualquer comentário acerca do risco. Assim, o Coordenador de Vigilância Sanitária, após uma consideração parecida com as anteriores, determinou a realização da avaliação do risco, nestes termos: 
Considerando que a conduta da empresa autuada deve contribuir ou dar causa ao RISCO SANITÁRIO, para que se efetive o cometimento da infração sanitária;

Encaminhe-se à Área Técnica para avaliação do RISCO SANITÁRIO, com posterior retorno a esta Coordenação. (Destaque no original).

Desta feita, os autos retornaram à área técnica e relatou-se o seguinte:

Concluímos que a autuada infringiu a legislação sanitária, provocando a existência de RISCO SANITÁRIO, pois não manteve instalações sanitárias em condições satisfatórias à sua utilização, possibilitando a ocorrência de agravos à saúde da comunidade portuária e da população do entorno do porto (município), trazendo risco à Saúde Pública. (Destaque no original).

d) O quarto processo apresentou a irregularidade de retirada de resíduos por empresa que não é detentora de Autorização de Funcionamento de Empresa (AFE), tipificada no artigo $2^{\circ}$, VII, da RDC nํㅜ 345, de 16 de dezembro de 2002, nestes termos:

Art. $2^{\circ}$. Ficam sujeitas à Autorização de Funcionamento, as empresas que prestem serviços de:

VII - segregação, coleta, acondicionamento, armazenamento, transporte, tratamento e disposição final de resíduos sólidos resultantes de veículos terrestres em trânsito por postos de fronteira, aeronaves, embarcações, terminais aquaviários, portos organizados, aeroportos, postos de fronteiras e recintos alfandegados;

Em avaliação da matéria de fato, o autuante manifestou-se:

A infração cometida pela empresa acima citada constitui risco sanitário, pois, contratou empresa sem autorização da ANVISA. Conforme Resolução-RDC n. 345, de 16 de dezembro de 2002, a empresa precisa ter todos os requisitos para atuar na atividade, pois presta serviço de saúde pública.

Diante do exposto, informo que a irregularidade cometida constitui risco sanitário.

Não obstante a manifestação do autuante, o Coordenador de Vigilância Sanitária, após realizar idêntica consideração feita no terceiro processo, determinou a realização da avaliação do risco pela área técnica, que inferiu:

Considerando o elevado RISCO SANITÁRIO representado pela manipulação indevida de tais resíduos, que combinado com a realidade epidemiológica da totalidade dos municípios do país, tem o poder de deflagrar surtos e epidemias;

Concluímos que, apesar da não ocorrência do dano efetivo, que se configuraria com a efetivação do agravo à Saúde Pública, a conduta da autuada revela-se potencialmente danosa. (Destaque no original). 
e) O penúltimo auto de infração foi lavrado pelo não cumprimento de uma notificação anterior que constatara, na área do refeitório, ausência de lavatórios providos de produtos líquidos para higienização das mãos, toalhas descartáveis e recipientes para resíduos tampados e com sacos plásticos.

Não há nos autos manifestação do autuante, de modo que apenas o Coordenador de Vigilância Sanitária refere-se ao risco, nesses termos:

Considerando que a conduta da empresa autuada deve contribuir ou dar causa ao RISCO SANITÁRIO, para que se efetive o cometimento da infração sanitária. (Destaque no original).

f) O sexto auto de infração verificou a "ausência de contendores brancos para o recebimento de resíduos infectantes provenientes das enfermarias das embarcações." Irregularidade tipificada no artigo 85, da RDC no 217, de 21 de novembro de 2001 :

Art. 85. É obrigatória a presença, nas áreas de Portos de Controle Sanitário, de contâineres, identificados, diferenciados externamente para resíduo "comum" ou "infectante", providos de tampas e em quantidade que atenda o previsto no Plano de Gerenciamento de Resíduos Sólidos aprovado, para fins de armazenagem de sacos acondicionadores recolhidos das embarcações e da prestação de serviços e produção e circulação de bens nestas áreas.

Sem manifestação do servidor autuante acerca do risco, o Coordenador de Vigilância Sanitária, depois de suas considerações habituais, encaminhou o processo para avaliação do risco pela área técnica, que concluiu:

Concluímos que existe RISCO SANITÁRIO, pois se constatou que a empresa não atuou de forma a cumprir as etapas necessárias ao correto manejo dos resíduos sólidos, propiciando a existência de criadouros de vetores em sua área, descumprindo a legislação sanitária, colocando em risco o Meio Ambiente e a Saúde Pública. (Destaque no original).

Ao receber de volta os autos, o Coordenador de Vigilância Sanitária salientou que a área técnica informou "existência de risco sanitário".

Cabe à autoridade julgadora realizar avaliação do risco para a imposição da pena e estabelecer sua graduação, devendo levar em conta a gravidade do fato, tendo em vista as suas consequências para a saúde pública. Por isso, o registro dessa verificação pelo autuante é parte integrante da decisão sobre o processo administrativo sanitário. 
Antes de pronunciar-se sobre o risco, a autoridade considerou que a área técnica manifestou-se sobre o risco sanitário quando essa definia procedimentos e traçava considerações sobre equipamentos, de acordo com o retirado do texto:

A área técnica manifestou-se acerca do risco sanitário, aduzindo que as Boas Práticas Sanitárias no Gerenciamento de Resíduos Sólidos devem constituir-se de um conjunto de procedimentos planejados, implantados e implementados a partir de bases cientificas, técnicas e normativas, com o objetivo de atender a preceitos de minimização de riscos, na geração de resíduos e proporcionar um encaminhamento seguro aos resíduos, de forma eficiente, visando a proteção dos trabalhadores, a preservação da saúde pública, dos recursos naturais e do meio ambiente.

Aduz ainda que (...) considerando que a contaminação do trabalhador se dá pelo contato direto com os resíduos sólidos ou pela massa de água por estes poluídas, a utilização correta de Equipamento de Proteção Individual (EPI) é o único meio seguro de garantir que o trabalhador não contaminará a si mesmo nem seus contactantes ou 0 ambiente em que circula.

Deste modo, as considerações finais sobre o risco sanitário constantes na decisão são as seguintes:

Vale lembrar que a empresa descumpriu normas sanitárias, estando sujeita às penalidades descritas na Lei $n^{\circ} 6.437 / 77$. Registre-se que 0 gerenciamento dos resíduos sólidos e a limpeza da área portuária é responsabilidade das empresas que administram os portos de controle sanitário, esclarecendo que a norma transgredida, por si só, já determina o risco sanitário que as administradoras de portos de controle sanitário podem incorrer. Por todas as razões expostas, mantenho esses AIS [autos de infração sanitária].

A empresa de Grande Porte - Grupo I é primária, no que se refere a anteriores condenações por infrações sanitárias, conforme certificado nos autos, devendo o risco sanitário de sua conduta ser considerado na dosimetria da pena.

\section{Discussão}

Observa-se que a forma aplicada para a caracterização do risco nos processos citados não se utilizou da avaliação de risco, porquanto não se constatou nos casos qualquer explicação mais completa com sentido científico.

Quando da verificação da matéria de fato realizada pelo autuante, nota-se que apenas no quarto processo houve manifestação daquele sobre o risco, devendose ressaltar que ela limitou-se à afirmação de que houve risco sanitário.

Nos demais casos, verifica-se que o Coordenador de Vigilância Sanitária protagonizou duas condutas. A uma, manifestou-se de forma sucinta; a duas, enviou o processo para a área técnica, para que esta se pronunciasse. Contudo, em ambas 
as situações percebeu-se que a avaliação do risco foi mais fundamentada no senso comum do que em explicações completas, de cunho científico, de forma que o autuado compreendesse perfeitamente o ilícito e suas possíveis consequências.

O sexto processo representa o único no qual se pode vislumbrar um incipiente tratamento científico do risco, no momento em que, além de ratificar o ato da empresa como contrário ao ditado pela norma, a área técnica afirmou que este propiciava a existência de criadouros de vetores.

Com relação à análise da autoridade julgadora, esta se ateve à manifestação da área técnica. Assim, apenas houve ponderações sobre a legislação e, ao fim, justificou-se a existência de risco sanitário por meio da transgressão da norma, sem qualquer referência às consequências efetivas para a saúde pública em cada situação.

Nesse contexto, não se pode olvidar que a Anvisa representa a porção da Administração que é dotada de conhecimentos científicos específicos e, assim, é especializada no que tange ao tema saúde. Não obstante, o que se nota é que, nos casos analisados, houve um gerenciamento do risco constatado, inobstante a ausência do tecnicismo científico característico das avaliações de risco e as evidentes ponderações sobre preocupações legais e sociais, fatores que exaltam o caráter discricionário da gerência do risco.

Sem um esclarecimento embasado cientificamente e, ao mesmo tempo, claro o suficiente para que os cidadãos compreendam as situações apuradas nos processos sanitários, não se realiza a transformação citada por Boaventura de Souza Santos (1995), na qual o conhecimento de senso comum legitimar-se-ia cientificamente.

A insuficiência de esclarecimentos técnicos quando da apuração do risco sanitário tanto enuncia um prejuízo ao interesse público - por deixar de explicitar uma maior legitimidade a uma sanção da Administração - quanto ao interesse privado por não ensejar ao infrator a devida compreensão dos efeitos da infração cometida.

Em virtude de expressar um critério objetivo e desprovido de expertise ou de conhecimentos técnicos, o conhecimento de senso comum deve fundir-se ao científico, para que a Administração cumpra o objetivo da vigilância sanitária no controle, na redução ou na eliminação dos riscos, de modo que seja capaz de efetivar 
a proteção à saúde sem cercear, arbitrariamente, direitos de pessoas físicas ou jurídicas que lidem com a circulação de bens e a prestação de serviços.

\section{Referências}

BRASIL. Lei no 8.080, de 19 de setembro de 1990. Dispõe sobre as condições para a promoção, proteção e recuperação da saúde, a organização e o funcionamento dos serviços correspondentes e dá outras providências. Disponível em: <http://www.planalto.gov.br/ccivil_03/leis/L8080.htm>. Acesso em 27 nov. 2012.

BRASIL. Lei no 6.437, de 20 de agosto de 1977. Configura infrações à legislação sanitária federal, estabelece as sanções respectivas, e dá outras providências. Disponível em: <http://www.planalto.gov.br/ccivil_03/leis/L6437.htm>. Acesso em 27 nov. 2012.

BRASIL. Lei no 9.782, de 26 de janeiro de 1999. Define o Sistema Nacional de Vigilância Sanitária, cria a Agência Nacional de Vigilância Sanitária, e dá outras providências. Disponível em: <http://www.planalto.gov.br/ccivil_03/leis/L9782.htm>. Acesso em 27 nov. 2012.

BRASIL. Anvisa. Resolução da Diretoria Colegiada - RDC $n^{\circ} 56$, de 6 de agosto de 2008. Disponível em: <http://www.brasilsus.com.br/legislacoes/rdc/14300-56?q=>. Acesso em 27 nov. 2012.

BRASIL. Anvisa. Resolução da Diretoria Colegiada - RDC n 345, de 16 de dezembro de 2002. Disponível em: <http://www.anvisa.gov.br/legis/resol/2002/345_02rdc.pdf>. Acesso em 27 nov. 2012.

BRASIL. Anvisa. Resolução da Diretoria Colegiada - RDC n 217, de 21 de novembro de 2001. Disponível em: <http://www.anvisa.gov.br/legis/resol/2001/217_01rdc.htm>. Acesso em 27 nov. 2012.

DELDUQUE, Maria Célia. Controle judicial da política pública de vigilância sanitária: a proteção da saúde no Judiciário. São Paulo: 2010. Tese de doutorado - Faculdade de Saúde Pública da Universidade de São Paulo, 2010. Disponível em <http://www.teses.usp.br/teses/disponiveis/6/6135/tde-08122010-140717/>. Acesso em 17 jan. 2013.

DI PIETRO, Maria Sylvia Zanella. Direito administrativo. São Paulo: Atlas, 2007. ISBN: 978-85-224-4611-7.

LUCCHESE, Geraldo. Globalização e regulação sanitária: os rumos da vigilância sanitária no Brasil. Brasília: Anvisa, 2008. ISBN: 9788588233393.

MIRANDA, Henrique Savonitti. Curso de direito administrativo. Brasília: Senado Federal, 2007. ISBN: 85-70182-48-1

National Research Council. Risk assessment in the government: managing the process. Washington, DC: National Academy Press, 1983 apud LUCCHESE, Geraldo. Globalização e regulação sanitária: os rumos da vigilância sanitária no Brasil. Brasília: Anvisa, 2008. ISBN: 9788588233393.

SANTOS, Boaventura de Souza. O social e o político na transição pós-moderna. São Paulo: Lua Nova, 1993. Disponível em <http://www.scielo.br/ 
scielo.php?script=sci_arttext\&pid=S0102-64451993000300010\&lng=en\&nrm=iso >. Acesso em 16 nov. 2012.

SANTOS, Boaventura de Souza. Introdução a uma ciência pós-moderna. Porto: Afrontamento, 1995 apud LUCCHESE, Geraldo. Globalização e regulação sanitária: os rumos da vigilância sanitária no Brasil. Brasília: Anvisa, 2008. ISBN: 9788588233393.

MOLAK, Vlasta. Fundamentals of Risk Analisis and Risk Manegement. Boca Raton: Lewis Publishers, 1997 apud LUCCHESE, Geraldo. Globalização e regulação sanitária: os rumos da vigilância sanitária no Brasil. Brasília: Anvisa, 2008. ISBN: 9788588233393.

WALDMAN, Eliseu Alves. Vigilância epidemiológica como prática de saúde pública. São Paulo, 1991. Tese de doutorado - Faculdade de Saúde Pública da Universidade de São Paulo, 1991. Disponível em <http://hygeia.fsp.usp.br/ hep5728/teses/TeseNew.pdf>. Acesso em 17 jan. 2013. 